\title{
Surgical Outcome and Prognosis of Spinal Missile injuries
}

\author{
Ali Hikmat Azeez*, Nashwan Yaseen Sallama* , Saad A. Yahya Alsaqa* \\ *Unit of Neurosurgery, Ibn-Sina Teaching Hospital , Ninevah Healh Direectorae , Mosul , Iraq \\ Correspondence: alihikmat_aziz@yahoo.co.uk
}

(Ann Coll Med Mosul 2021; 43 (1):55-59).

Received: $5^{\text {th }}$ Janu. 2021; Accepted: $1^{\text {st }}$ March 2021.

\begin{abstract}
Background: The spinal cord is so sensitive to injury. Once it is damaged; it shall lose its ability to repair itself .Unfortunately spinal cord injuries (SCl)are common in Iraq . It could be either complete or incomplete $\mathrm{SCl}$. In the complete injury there is a total loss of sensation and motor function in the level below the site of the injury, while in the incomplete one there is some remaining neurological functions below the level of the injury.

Objectives: The aim of this study is to compare the surgical and conservative management of complete and incomplete spinal cord Injuries due to missile in Mosul city.

Patients and methods: A case series study of (60) patients with missile cord injury of the spine who were managed in the Neurosurgical Department at Ibn-Sina Teaching Hospital in Mosul from August 2011 August 2013. The mean patient age was 30 years. Thirty three (55\%) patients were surgically treated. The mean time of follow up was 9 months ranged from 6-18 months. All patients had complete radiological assessment, CT scan and one patient with through and through bullet injury magnetic resonance imaging( MRI) was done after initial resuscitation.

Results: All patients with complete spinal cord injury did not improved after non-surgical management, after surgical removal of bullet and it's pressure effect from the spinal cord just one case with conus medullaris injury gets improvement. Those with incomplete injuries show good improvement after surgical management. Conclusion: Conus medullaris and cervical injuries show a better outcome in surgical treatment than those out surgical intervention in incomplete spinal cord injuries. There were no difference between the outcomes of surgical and non- surgical management of complete neurological injuries of the spinal cord.
\end{abstract}

Keywords: Missile injuries, spinal cord Injuries, surgical management and non-surgical management.

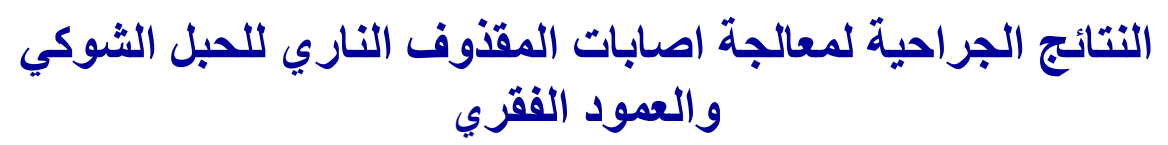

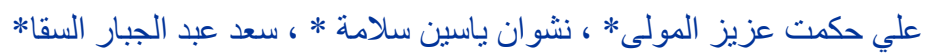

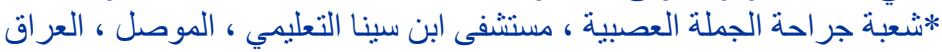

الخلاصة

خلفية الدراسةة : الحبل الثوكي عالي التحس للإصابة ولا تستطيع خلاياه بناء نفسها بعد الاصابة . اصابات الحبل الثوكي لسوء

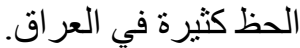

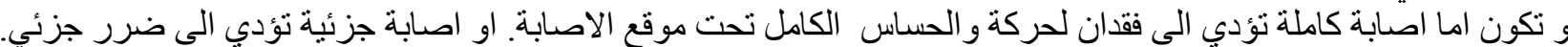

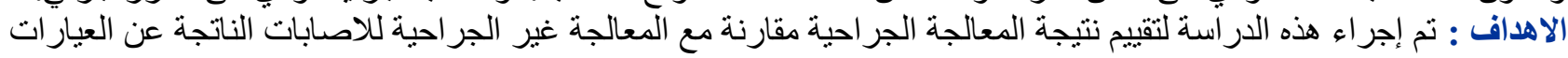

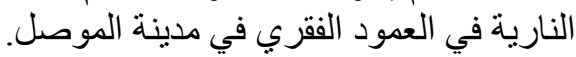

المحيط : تم إجر اء هذه الدئ الدر اسة في وحدة الجر احة العصبية في مستشفى ابن سينا التعليمي في مدينة الموصل وللفترة من شهر

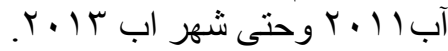

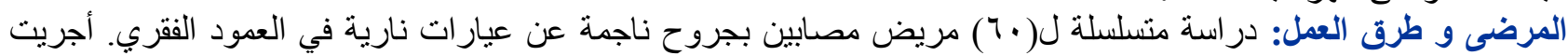

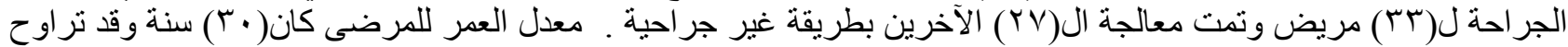

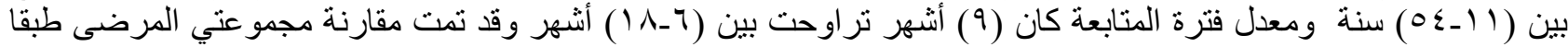




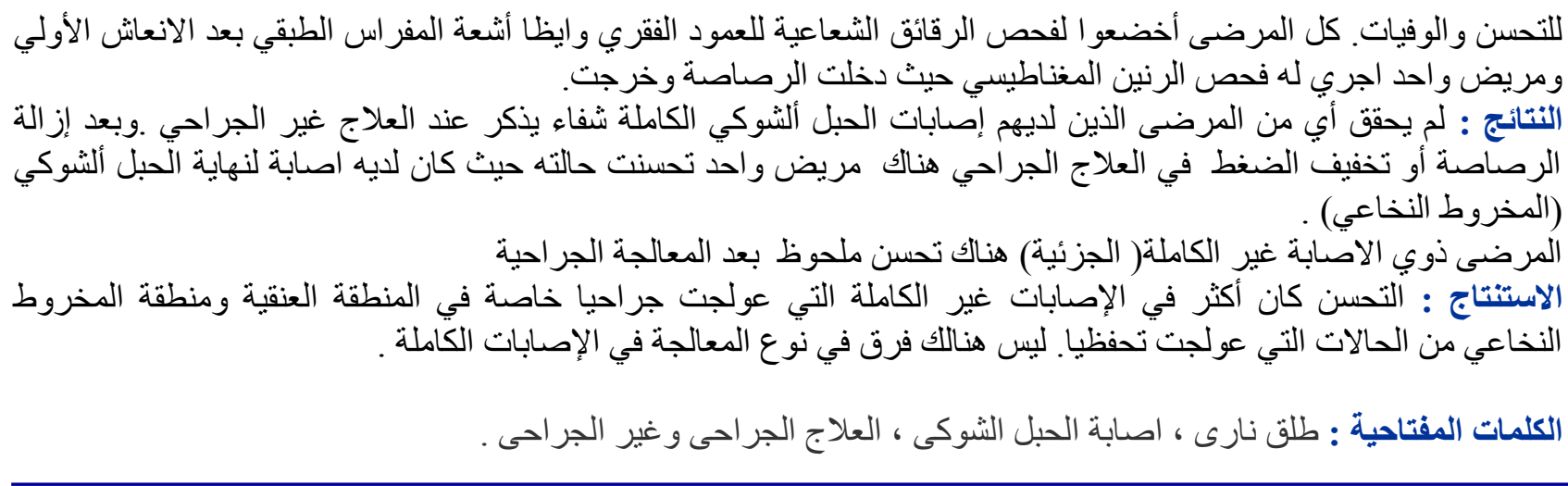

\section{INTRODUCTION}

A Ithough spinal missile injuries (MIs) are not so common in most countries, they are unfortunately common in cities of Iraq due to wars. Traumatic spinal cord injuries $(\mathrm{SCl})$ are a catastrophe for the individual concerned. It leads to Para- or tetraplegia , sphincter and sexual dysfunction. 1

The first who described spinal injuries was an Egyptian Edwin Smith Papyrus from 2500 BC, as an untreatable condition. After that, Hindu wrote up about $1800 \mathrm{BC}$ also mentioned $\mathrm{SCl}$ and described traction as an approach for treatment. Later on Hippocrates described $\mathrm{SCl}$ in his Corpus and described traction devices to straighten dislocated vertebrae.

In 1762, Andre Louis conducted surgical removal of a bullet from the lumbar spine of a victim, then he could move his legs successfully. ${ }^{2}$

Gilpin Smith half a century later, performed laminectomy for a patient with $\mathrm{SCl}$ with good result. Despite all this history, the idea that $\mathrm{SCl}$ is an untreatable condition remained dominant until the early in the past century. ${ }^{3}$

The spinal cord is very delicate, and does not have the ability to regenerate itself, if it is damaged. The $\mathrm{SCl}$ occur when there is damage to the spinal cord either from trauma, loss of its normal blood supply, or compression of any type.

$\mathrm{SCl}$ either complete or incomplete injury. In the complete one there is complete loss of motor function and sensation in the body below the level of the injury. In incomplete $\mathrm{SCl}$ there is some remaining function below the level of the injury.

$\mathrm{SCl}$ in the neck can cause paralysis of both upper and lower limbs. If it is in the lower back, it could cause paraplegia of both lower limbs .

For diagnosis of a SCl, a medical history about the time of injury. since as soon as the patient obtains treatment, the better the likelihood of recovery. Past medical history of any prior back, neck or limb disease, any weakness, loss of bladder or bowel control, loss of sensation, and any other medical conditions previously. ${ }^{5}$

Also physical examination should include sensation testing to see if touch is intact in the upper and lower limbs as well as testing power of muscles and reflexes in the upper and lower limbs. The patient should be kept on a spine backboard or in a cervical collar for immobilization, until to be sure whether or not the patient has an injury of the spinal cord. ${ }^{6}$

The decision considering the kind of treatment should be made deliberately, in regards to factors such as: grade of $\mathrm{SCl}$, age of the patient, general condition and accompanying injuries. The initial treatment is an integral part of the trauma evaluation, dealing with airway, breathing and circulation in order to achieve stable patient condition( normal vital signs) should be the primary goal according to Advance trauma life support ATLAS.

The surgical intervention for patients with $\mathrm{SCl}$ is kept for patients with persistent CSF fistulae, progressive neurological deterioration, and incomplete spinal cord injuries with active neural compression from either an inter vertebral disk, a bullet, or a hematoma within the spinal canal. ${ }^{7}$ and for migrating bullet, lead toxicity, spinal instability as a late complication.

Otherwise conservative management is considered.

\section{OBJECTIVES}

The aim of study is to compare surgical and conservative management of complete and incomplete spinal cord injuries due to missile in Mosul city. 


\section{PATIENT AND METHODS}

This is a case series study of sixty patients with Mls of the spine who were managed at the Neurosurgical unit, Ibn-Sina Teaching Hospital in Mosul for the period from August 2011 to August 2013.

Male to female ratio was 5.8:1 with mean age 30 years.

The distribution of injuries according to the anatomy of spine is shown in (figure 1) the cervical spine was (20\%), the dorsal spine was $(55 \%)$, and $(25 \%)$ for the lumbosacral spine injuries.

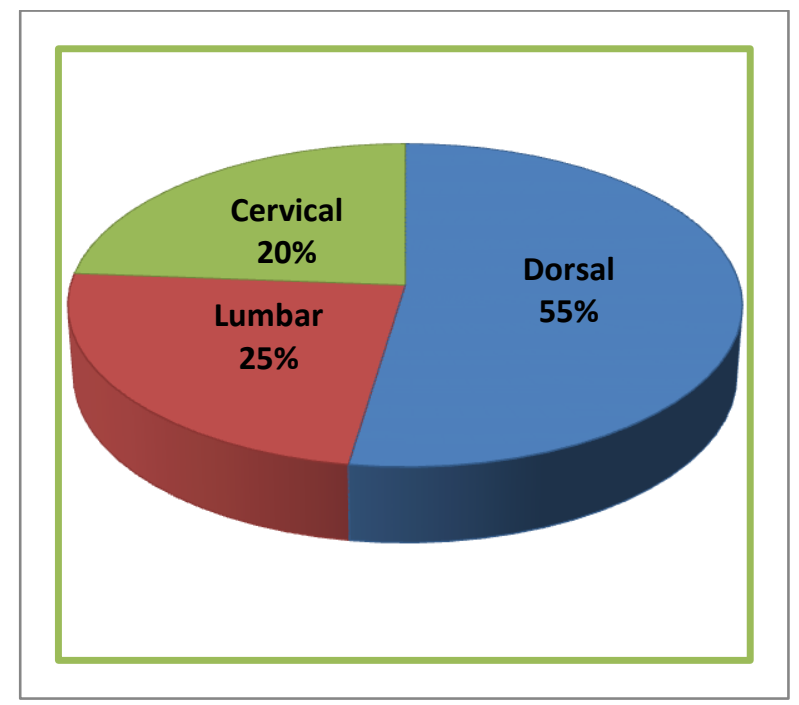

Figure (1) Frequency distribution of cases according to the anatomical level of injury

All patients were evaluated using plain radiograph, computed tomography $(\mathrm{CT})$, magnetic resonance imaging $(\mathrm{MRI})$ for one patient with through and through injury , and electrophysiological study were also performed for follow-up the progression of the lesion.

\section{Patients were divided into two groups:}

Group (A) Those with incomplete injury including 33 patients $(55 \%)$ of all cases with (Mls). 24 patients $(72 \%)$ underwent surgery, while the rest were managed non-surgically as shown in (Table 1 and 2).

Group (B) Those with complete injury (complete loss of all motor and sensory function below the level of injury).They were 27 patients out of all cases with spinal Mls received (45\%). 9 patients (33\%) were explored surgically, while the others 18 patients (67\%) were managed non-surgically.
Table 1 : distribution of injuries in the studied patients according to anatomical level of injury and severity

\begin{tabular}{|l|l|l|l|l|l|l|}
\hline $\begin{array}{l}\text { Level of } \\
\text { injury }\end{array}$ & \multicolumn{2}{|l|}{$\begin{array}{l}\text { Complete } \\
\text { injury }\end{array}$} & \multicolumn{2}{l|}{$\begin{array}{l}\text { Incomplete } \\
\text { injury }\end{array}$} & \multicolumn{2}{l|}{ Total } \\
\cline { 2 - 7 } & NO. & $\%$ & NO. & $\%$ & NO. & $\%$ \\
\hline Cervical & 5 & 18.5 & 7 & 21.3 & 12 & 20.25 \\
\hline Dorsal & 19 & 70.3 & 14 & 42.4 & 33 & 56.0 \\
\hline Lumbar & 3 & 11.2 & 12 & 36.3 & 15 & 23.75 \\
\hline Total & 27 & 100 & 33 & 100 & 60 & 100 \\
\hline
\end{tabular}

Timing of Surgery The proper time of deciding surgery in cases with $\mathrm{SCl}$ depends on the associated injuries. However, surgery should be performed at convenient time once systemic stabilization is achieved usually within $5-10$ days. ${ }^{9}$

Post-operative period management Upon reversal of anesthesia base line assessment of patient condition was performed. The postoperative care includes: drainage of pulmonary secretions and promoting venous drainage from lower extremities and protecting skin integrity. Patients received at least 14 days course of antibiotics especially if there has been trans-pleural or trans-peritoneal trajectory with bowel injury where rapid mobilization was essential and multidisciplinary rehabilitation instituted within (24 48 ) hours post-operatively. The follow up of all cases was 9 months ranged from (6-18) month

Statistical Analysis Fisher exact test was used to compare the correlation between the surgical and conservative groups, and groups, which were subdivided according to anatomical regions.

\section{RESULT}

After surgical intervention of the 24 cases with incomplete injuries, improvement was encountered in 12 patients $(50 \%)$. On the other hand other 9 patients with non-surgical management one patient had improvement as shown in Table 2.

On the other hand, only one patient out of nine (11.1\%)with complete injury who were managed surgically has got an observable improvement Meanwhile ,no improvement to those were managed conservatively as shown in Table3. 
Table 2 The clinical improvement in patients with incomplete spinal cord injuries due to missile according to the type of management and anatomical level.

\begin{tabular}{|c|c|c|c|c|c|c|c|}
\hline \multirow{2}{*}{ Level of injury GSWs } & \multicolumn{3}{|c|}{ Surgical management } & \multicolumn{3}{c|}{ Non-surgical management } & \multirow{2}{*}{ * $p$-value } \\
\cline { 2 - 7 } & NO. & $\begin{array}{c}\text { No. of } \\
\text { improved }\end{array}$ & $\%$ & NO. & NO. of improved & $\%$ & \\
\hline Cervical & 6 & 5 & 83.3 & 1 & 0 & 0.0 & 0.001 \\
\hline Dorsal & 9 & 1 & 11.1 & 5 & 0 & 0.0 & 0.001 \\
\hline Lumbar & 9 & 6 & 66.7 & 3 & 1 & 33.3 & 0.001 \\
\hline Total & 24 & 12 & 50 & 9 & 1 & 11.1 & 0.001 \\
\hline
\end{tabular}

Fisher test ${ }^{\star}$

Table 3 The clinical improvement in patients with complete spinal cord injuries due to missiles according to the type of management and anatomical level.

\begin{tabular}{|l|l|l|l|l|l|l|l|}
\hline & \multicolumn{3}{|l|}{ Level of injury } & \multicolumn{2}{l|}{ Non-surgical management } & \multicolumn{2}{l|}{ p-value $^{*}$} \\
\hline & NO. & $\begin{array}{l}\text { No. of } \\
\text { improved }\end{array}$ & $\%$ & NO. & $\begin{array}{l}\text { NO. of } \\
\text { improved }\end{array}$ & $\%$ & \\
\hline Cervical & 1 & 0 & 0.0 & 4 & 0 & 0.0 & 1.00 \\
\hline Dorsal & 5 & 0 & 0.0 & 14 & 0 & 0.0 & 1.000 \\
\hline Lumbar & 3 & 1 & 33.3 & 0 & 0 & 0.0 & 0 \\
\hline Total & 9 & 1 & 11.1 & 18 & 0 & 0.0 & 1.000 \\
\hline
\end{tabular}

* Fisher test

\section{DISCUSSION}

There has been a dramatic increase in the number of Mls managed in the Unit of Neurosurgery at Ibn-Sina Teaching Hospital in Mosul city, Iraq. The long- term functional disability as a sequence of $\mathrm{SCl}$ resulting from missile injury to the spine is an important problem in our city that needs to be addressed in our society.

Although SCl are not so common in most countries, they are unfortunately common in cities of Iraq due to wars, this results disagree with AS Otom et al ${ }^{10}$ who have no cases of $\mathrm{SCl}$ resulted from war injury because Jordan has a peaceful period for more than 20 years.

The male to female ratio was 5.8:1 which is higher than in other study ${ }^{11}$ as far as male serves in military and more to be outside house, where most of the women are housewives.

As in a study reported by Karamehmetoglu ${ }^{12}$, the peak incidence of $\mathrm{SCl}$ is within the "age group of $30 \pm 10$ years". Thoracic SCl was the most common level of $\mathrm{SCl}$ with a frequency $55 \%$, Lumbar SCl frequency $25 \%$ and Cervical SCI $20 \%$.as in Fig 1

Table 2 and 3 shows the thoracic spine is the most affected ( $55 \%$ of patients) but there is no significant clinical improvement $(p=1.000)$ in patients with Complete spinal injuries due to missiles at this region because of the risk of large vessel damage, lung, and heart, a small number of patients can be transmitted to department of neurosurgery after a thoracic injury.

Until evaluation of vessel or visceral organ injuries and stabilization of vital signs is completed, Spinal injuries stay secondarily managed, these results agree with Agarwal et al. ${ }^{13}$

In this study table 2 show significant improvement in incomplete $\mathrm{SCl}$ at cervical, dorsal and lumbar regions this results agree with Stauffer et al $^{14}$, who treated 79 patients with $\mathrm{SCl}$ with gun shots with incomplete neurological deficit of these, 
$71 \%$ had some neurological improvements after surgery.

This study indicates that surgical intervention may not significantly produce the final functional recovery, when the spinal cord damage is complete The most important indication for conducting surgery was to relieve spinal cord compression caused by primary or secondary injury .

A finding which is similar to the result obtained in other researchers. ${ }^{15}$

\section{CONCLUSION}

* There were no significant differences in the outcome of surgical and non-Surgical management of complete spinal cord injury due to missiles.

* The bullet fragment in the cervical or conus medullaris region in the presence of incomplete neurological injury should be explored if there is evidence of compression with neurological deterioration.

* Surgical management offers better result than would non-surgical management do.

\section{REFERENCES}

1.Lifshutz, J., Colohan, A. brief history of therapy for traumatic spinal cord injury". Neurosurgery Focus. 16 (1 E5): E5. doi:10.3171/foc.2004;16.1.6. PMID 1526478 3.

2. National Spinal Cord Injury Statistical Center, Fact and Figures at a Glance. Birmingham, AL; University of Alabama at Birmingham, 2016

3. Holtz MD, PhD Richard Levi, MD,PhD 20 -72010. Spinal Cord Injury Andersp 5-6.

4.Chittibonia P., Banerjee AD., Zhang, S., Caldito, G., Willis, B., How bullet trajectory affect out comes of civilian gunshot injury to the spine. Journal of clinical neuroscience .2011; 18:16301633.

5.Morganti-Kossmann, Raghupathi\& Maas 2012, "Traumatic Brain and Spinal Cord Injury challenges and developments" Cambridge University press first published 2012p. 229.

6. Fallah, Dance \& Burns 2012Advanced Critical Care Nursing , p. 235.

7.Gupta, S., Senger, RL., Wandering intra-spinal bullet.Br J Neurosurg 1999; 13:606-607.

8.Bell, RS., Neal, CJ., Tingo, J., et al: Traumatic brain and spinal column injury: a5-year study of the impact blast and other military grade weaponry on the central nervous system. Trauma 66(4):S104-S111,2009
9. Edword, C., Benzel SPINE SURGERY third edit. Publish June 2012 p717.

10. Otom, AS., Doughan, AM., Kawar, JS., and Hattar, EZ., Traumatic spinal cord injuries in Jordan \pm an epidemiological study. The Royal Jordanian Rehabilitation Centre, King Hussein Medical Centre, Amman-Jordan. 1997; 35, $253 \pm$ 255.

11. Jenkins, D., Dougherty, P., The Effects of Bullets. Edited by: Mahoney, PF., Ryan, JM., Brooks, AJ., Schwab, CW., Ballistic Trauma. London: Springer Verlag; 2005: 40-44.

12. Karamehmetoglu, SS. et al. Traumatic spinal cord injuries in Istanbul, Turkey: an epidemiological study. Paraplegia 2000; 33: 469 \pm 471 .

13. Agarwal, P., John, F., Kalil G., piazza, M., Brian, P., Jayesh, P., Neil R., et al: Surgical Neurology International 2016 page S1069S1098. Bono, CM., Heary RF. Gunshot wounds to the spine. Spine J. 2004;4:230- 40.

14. Stauffer, ES., Wood, RW., Kelly, EG., Gunshot wounds of the spine: the effects of laminectomy. J Bone Joint Surg Am 1979; 61: 389-392.

15. Bagnall, AM., Jones, L., Duffy, S., Riemsma, RP., (2008) Spinal fixation surgery for acute traumatic spinal cord injury. Cochrane Database Syst Rev (1): CD004725. 